\title{
CiEN AÑOS DE ARQUEOLOGÍA FUNERARIA EN EL ESTRECHO DE GIBRALTAR: NUEVAS INVESTIGACIONES EN LA NECRÓPOLIS DE Baelo Claudia (TARIFA, CÁdiz)
}

En este trabajo abordamos el estudio de la necrópolis oriental de Baelo Claudia (Tarifa, Cádiz) a partir de los trabajos arqueológicos y de interpretación de las antiguas intervenciones que llevamos a cabo desde la Universidad de Alicante. Asimismo, junto con los resultados de la última excavación, se plantean nuevas lecturas sobre el paisaje funerario, la religiosidad y la etnicidad, así como sobre la tipología monumental y los ajuares.

Palabras clave: Estrecho de Gibraltar, Baelo Claudia, necrópolis, ritual funerario.

\section{A Century of FUnerary archaeology in the Strait of Gibraltar: neW inVESTigations in the necropolis of Baelo Claudia (Tarifa, Cádiz)}

The new archaeological research conducted by University of Alicante in the Eastern necropolis of Baelo Claudia (Tarifa, Cádiz) are presented in this paper. Drawing on renewed reinterpretations of ancient excavations which have been enriched with the results of recent archaeological works, new readings on funerary landscape, religion and ethnicity are proposed.

Key words: Straits of Gibraltar, Baelo Claudia, necropolis, burial practices.

Pocos yacimientos arqueológicos españoles cuentan con una tradición científica centenaria como Baelo Claudia, la ciudad hispanorromana emplazada en la ensenada de Bolonia (Tarifa, Cádiz). La investigación sobre el solar de la vieja Baelo arrancó a principios del s. XX y durante cien años ha brindado una formidable producción científica y ha aportado un enorme dossier documental para el conocimiento del mundo hispanorromano. Esta producción se cimenta en el proyecto científico y académico del arqueólogo francés Pierre Paris y en la École des Hautes Études Hispaniques (EHEH), posterior Casa de Velázquez.

Aunque la citada institución viniese tutelando en España desde su fundación en 1909 los trabajos de diversos arqueólogos galos (Cressier y Moret 2007), el gran proyecto científico arrancaría en 1914 con la elección, por parte de P. Paris, del yacimiento de Baelo para centrar los estudios. Se trató de un proyecto que, ante todo, se adecuó a los intereses de la EHEH ya que garantizaba su continuación por un dilatado período de tiempo (Maier 1999: 243).

A pesar de que la Junta Superior de Excavaciones y Antigüedades autorizara los trabajos de excavación en el yacimiento en 1914, éstos no comenzarían hasta 1917, prolongándose cinco años seguidos, hasta 1921. Desde un primer momento, P. Paris, que dirigió personalmente los trabajos, quedó impresionado por las posibilidades que ofrecía el yacimiento, tanto por su emplazamiento como por su conservación. La existencia de una necrópolis al E de la ciudad, en la que aún se conservaba en pie 


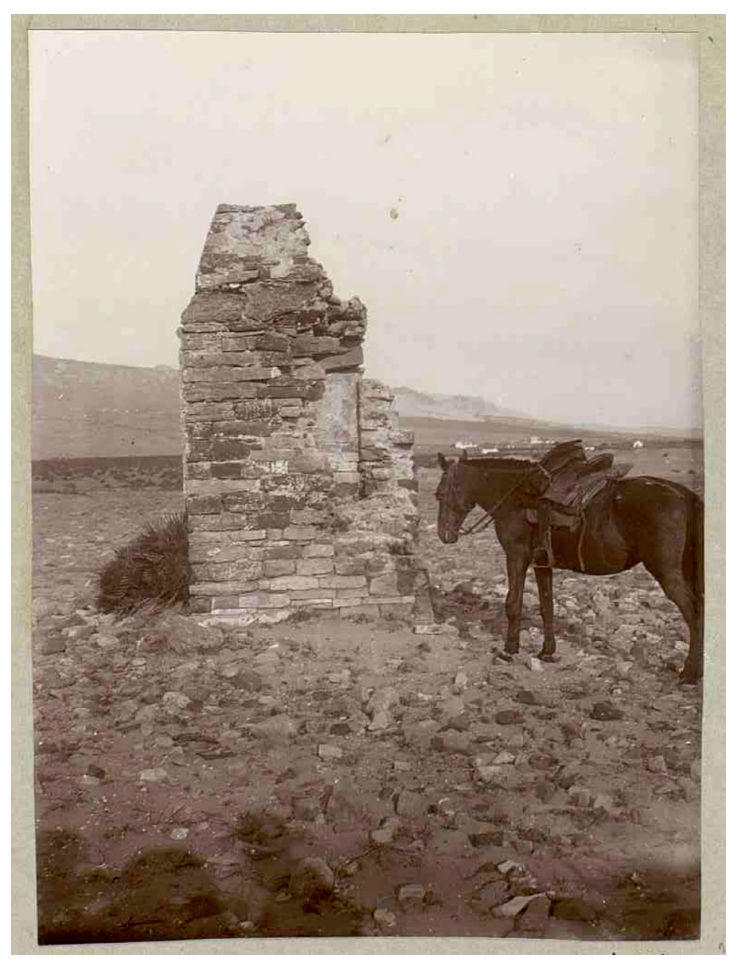

Fig. 1. Monumento turriforme llamado Hornillo de Santa Catalina. Fotografía de E. Romero de Torres (1909).

un imponente monumento de más de $4 \mathrm{~m}$ de altura (fig. 1), conocido como Hornillo de Santa Catalina, desembocó en la invitación de P. Paris a su amigo y veterano investigador Jorge Bonsor (Maier 1999: 242). Este último, con amplia experiencia en el estudio de necrópolis, dirigió las labores de excavación, documentando en pocos años más de mil enterramientos. Esta tarea permitió un amplio conocimiento de la tipología sepulcral y de los rituales, con lecturas aún vigentes en algunos aspectos (Paris et al. 1926).

Paralelamente no sería justo dejar de reconocer en este sucinto recorrido historiográfico a otro personaje: el R.P. jesuita Julio Furgus, también arqueólogo y coleccionista de origen francés que residía en Orihuela (Alicante) y que desarrolló diversos trabajos en la ciudad romana con anterioridad a los de la EHEH (Furgus 1907). Las exploraciones que J. Furgus llevó a cabo le llevaron a identificar dos grandes áreas sepulcrales, centrando sus excavaciones en la necrópolis occidental y manifestando su potencialidad arqueológica con la documentación de unos 30 sepulcros con sus respectivos ajuares (Furgus 1909).
De hecho, fueron los trabajos de J. Furgus los que introdujeron Baelo Claudia en los foros nacionales (García y Muñoz 2009), al aparecer publicadas noticias y diversos estudios en el Boletín de la Real Academia de la Historia (Fita 1902 y 1908). El académico Enrique Romero de Torres, tras recibir el encargo del Ministerio de Instrucción Pública para la redacción del Catálogo Monumental de España - Provincia de Cádiz, se hizo eco de los trabajos del jesuita, incluyendo el yacimiento dentro de su compendio (Romero de Torres 1918). No se puede desdeñar el hecho de que todos estos trabajos fuesen conocidos previamente por P. Paris, lo que sin duda alguna debió condicionar, en parte, la elección del yacimiento para el desarrollo de la misión francesa. Sin embargo, en cuanto a lo que aquí nos interesa, que es el estudio del mundo funerario baelonense, cabe apuntar que tanto J. Bonsor como P. Paris se interesaron por la necrópolis oriental, mientras que Furgus se había centrado en la occidental.

Desde luego, esta elección fue todo un éxito y los trabajos de excavación de J. Bonsor documentaron tal cantidad de sepulcros que una de las dos monografías dedicadas a la publicación de los resultados hubo de dedicarse en exclusiva a la necrópolis (Paris et al. 1926). La espectacularidad de los resultados no sólo se plasmó en la riqueza de los hallazgos, sino también en la experiencia aportada por el propio J. Bonsor. A pesar de no haber identificado relaciones estratigráficas, su exquisita metodología de excavación, así como los levantamientos planimétricos, los dibujos a escala de cada uno de los sepulcros (VV.AA. 2009) y el uso de la técnica fotográfica, convirtieron su excavación en una de las más avanzadas metodológicamente de la, por entonces, incipiente ciencia arqueológica española (Díaz-Andreu 1997).

A pesar del interés del proyecto y del éxito obtenido, P. Paris se vio forzado a suspender la actividad tras la finalización de la campaña de 1921, debido a que no contaba con personal técnico suficiente (Cressier y Moret 2007: 349). Ello, junto a diversos problemas de inestabilidad política que desembocaron en el estallido de la Guerra Civil en 1936, generó un paréntesis en las actuaciones de la misión francesa en Baelo hasta la década de 1960. La reanudación de las intervenciones, ya desde la Casa de Velázquez, tuvo lugar en 1966 y se extendieron hasta 1990 de manera ininterrumpida, a lo largo de 23 campañas (Sillières 2005). Durante éstas se puso al descubierto buena parte del área monumental 
visible hoy día. A lo largo de este segundo gran período de investigaciones en la ciudad, las necrópolis quedaron en un segundo plano de la investigación (García 2007). En la segunda mitad del s. XX, la prioridad consistió en resolver problemas cronológicos a través de la estratigrafía y los estudios cerámicos (Sillières 2005; Domergue 2006).

Aun así, y a pesar de que existió mayor interés por los aspectos urbanos o por los relacionados con las actividades económicas derivadas de las industrias de salazones, sí fueron acometidas varias intervenciones puntuales en la necrópolis oriental para resolver igualmente cuestiones cronológicas (Bourgeois y del Amo 1970). Fundamental en este sentido fueron las campañas desarrolladas por J. Remesal en 1973 y 1974, publicadas de manera monográfica en la colección Excavaciones Arqueológicas en España (Remesal 1979). Durante estas excavaciones se consiguió localizar un área cementerial intacta compuesta por varios monumentos y varias decenas de enterramientos simples. Gracias a esta excavación se obtuvo la primera secuencia estratigráfica del área sepulcral y se realizaron los primeros estudios de materiales arqueológicos en contexto claro. Finalmente, subrayar que en los últimos años del pasado siglo y en los primeros de la nueva centuria, el estudio del mundo funerario se ha visto supeditado a la realización de intervenciones no programadas, sino vinculadas a las tareas de apoyo a la conservación y puesta en valor. Así pues, se han desarrollado diversas excavaciones con motivo de la creación del nuevo trazado para visitantes del Conjunto Arqueológico (Arévalo et al. 2006), que han permitido caracterizar las fases tardías y mensurar el área sepulcral de época tardorromana.

\section{EL PROYECTO DE ESTUDIO Y DE RECUPE- RACIÓN DE LA NECRÓPOLIS ORIENTAL (MBC-2009-2017)}

El proyecto referido se centra en la recuperación de una de las necrópolis de la ciudad hispanorromana de Baelo Claudia y en la publicación de nuevos datos resultado de la estrecha colaboración entre equipos de investigación procedentes de dos instituciones (Área de Arqueología de la Universidad de Alicante y Conjunto Arqueológico de Baelo Claudia). Los trabajos de campo que venimos desarrollando desde 2009 han constado de dos tipos de actuación principalmente: una centrada en la prospección, limpieza y re-excavación, a través de varias actividades puntuales (2009-2011) y otra de excavación arqueológica en sí, que desarrollamos desde 2012 de forma sistemática. Esta última se ha enmarcado ya dentro de la programación del Proyecto General de Investigación MBC-Muerte y Ritual funerario en Baelo Claudia (Tarifa, Cádiz) autorizado por la Junta de Andalucía.

Desde el punto de vista teórico, nuestro proyecto se centra en el estudio de la necrópolis hispanorromana de Baelo (en su sector suroriental) a partir de la reconsideración de la perduración de rasgos religiosos y funerarios púnico-mauritanos y en la hibridación de éstos con los elementos autóctonos, visibles tanto en la tipología de enterramientos como en la ordenación espacial de los sepulcros (Prados y García 2009; Muñoz et al. 2009), así como los posteriores aportes itálicos a lo largo del s. I d.C.

Baelo Claudia supone la culminación de un complejo proceso urbanístico en la ensenada de Bolonia iniciado en el s. VIII a.C., según demuestran recientes investigaciones (Moret et al. 2010; Prados et al. 2012). Con un

Fig. 2. El Estrecho de Gibraltar desde el O. En el centro, Baelo frente a Tingis.

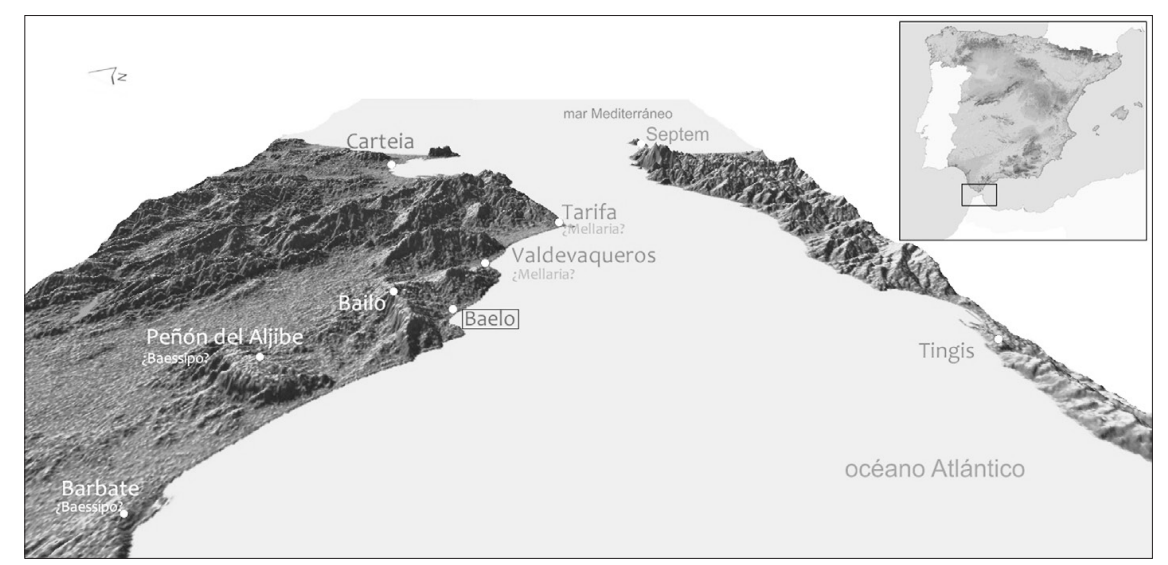


núcleo originario en el oppidum de la Silla del Papa, probablemente la Bailo prerromana de las célebres amonedaciones bilingües, aquéllas que emplearon una grafía definida como púnica aberrante, neopúnica o númida por los especialistas, Baelo fue el resultado de la evolución del sustrato autóctono y de su interrelación con la llegada sucesiva de elementos poblacionales alóctonos (Bendala 2006; Moret et al. 2008; Moret et al. 2010) siempre vinculados con el desarrollo de las actividades económicas, fundamentalmente pesquero-conserveras y con una espléndida posición geoestratégica a las puertas del océano Atlántico y frente a Tingis (fig. 2).

El proyecto de investigación abarca el estudio de las necrópolis partiendo del desarrollo de diversas actividades puntuales consistentes en la limpieza superficial de las estructuras excavadas a principios del s. XX en la necrópolis oriental y la elaboración de un levantamiento topográfico general. En este plano se han incluido la totalidad de las tumbas emergentes y visibles en superficie de todo el espacio funerario oriental, al $\mathrm{N}$ y al $\mathrm{S}$ de la vía de acceso a la ciudad. Además, para la realización de estas actuaciones, se ha aprovechado un material inédito y de gran interés como es el dibujo original realizado por $\mathrm{J}$. Bonsor y P. Paris conservado en el Archivo General de Andalucía (VV.AA. 2009) y de cuyo análisis hemos tenido ocasión de avanzar algunos aspectos fundamentales en recientes publicaciones (Muñoz et al. 2009; Prados y García 2010; Prados 2011). Por otro lado, se han estudiado materiales inéditos procedentes de otras actuaciones en la necrópolis, como los pertenecientes a la Colección Furgús, conservados en el MARQ (Museo Arqueológico Provincial de Alicante) y en el Museo de Orihuela (Alicante) y se ha procesado informáticamente todo el material gráfico original generado durante las intervenciones de la Casa de Velázquez en la necrópolis.

\section{EL PAISAJE FUNERARIO DE LA NECRÓPOLIS ORIENTAL}

No cabe duda de que el análisis arqueológico de las necrópolis de la ciudad hispanorromana de Baelo (fig. 3) resultará fundamental para tratar de comprender el carácter híbrido de la población que habitó un enclave urbano ubicado en un área liminal, en el confín occidental del imperio romano, surgido de la mezcla de componentes locales con otros de procedencia africana e itálica (Prados 2011). Ésta es la razón fundamental por la que pensamos que se debe acudir al estudio de las manifestaciones funerarias para tratar de abordar el discutido problema de las perduraciones púnicas en esta ciudad, aparentemente romana en lo que a su imagen urbana se refiere, al menos en sus imágenes identitarias simbólicas (Zanker 2000: 25) y la incidencia que sobre esas perduraciones debió tener el advenimiento posterior de élites más romanizadas (Bendala 2006; García 2008; Jiménez 2008; Bendala 2009; Padilla 2010; Bendala 2010).

Ya hemos apuntado que una de las labores desarrolladas ha sido la elaboración de una planimetría general de la necrópolis oriental. En ella, por vez primera, se han unificado los enterramientos aún visibles exhumados en las primeras campañas arqueológicas de principios del s. XX con los procedentes de las campañas de los años sesenta y setenta, y los excavados por nosotros mismos en 2012, pudiendo referenciar por métodos informáticos y topográficos los que no se conservan hoy, pero que fueron dibujados por J. Bonsor (Prados 2011: 196 y fig. 4). Las conclusiones aquí referidas derivan de la lectura arqueológica que este nuevo material ha permitido acometer, al que sí hemos tratado de aplicar ciertos avances conceptuales. Entre estos avances están los de considerar el paisaje funerario de la necrópolis como un todo, dotado de un sentido unitario basado en su carácter especial, así como tratar de determinar un conjunto de espacios jerarquizados en los que se documentan diferentes modelos de enterramiento y diversos elementos de tipo religiosofunerario.

Una de las cuestiones a valorar es la disposición de sepulturas en distintos sectores separados por espacios estériles, al menos entre las que se pueden agrupar dentro de una cronología altoimperial. Dicho fenómeno pudo responder a patrones espaciales o de jerarquización y pudo plasmar ciertas conductas socio-familiares. La ubicación jerarquizada de los sepulcros, en función de su mayor o menor cercanía a la ciudad o a la vía principal de comunicación, puede mostrar, con probabilidad, el reflejo post mortem de unidades gentilicias o familiares -quizás étnico-identitarias-, que pudieron constituir el sistema de agrupamiento tradicional de los habitantes de Baelo Claudia en ese periodo que, por otro lado, resulta ser el mejor conocido.

Pero ¿de qué naturaleza son las diferencias que refleja esta jerarquización, unida a las diferencias apreciables en el ritual funerario? Hoy, al investigar una necrópolis urbana conviene señalar que los distintos elementos de estudio (rituales, tipos de tumbas, niveles de riqueza, 
Fig. 3. Baelo Claudia y las áreas funerarias localizadas. A la derecha, la necrópolis oriental.

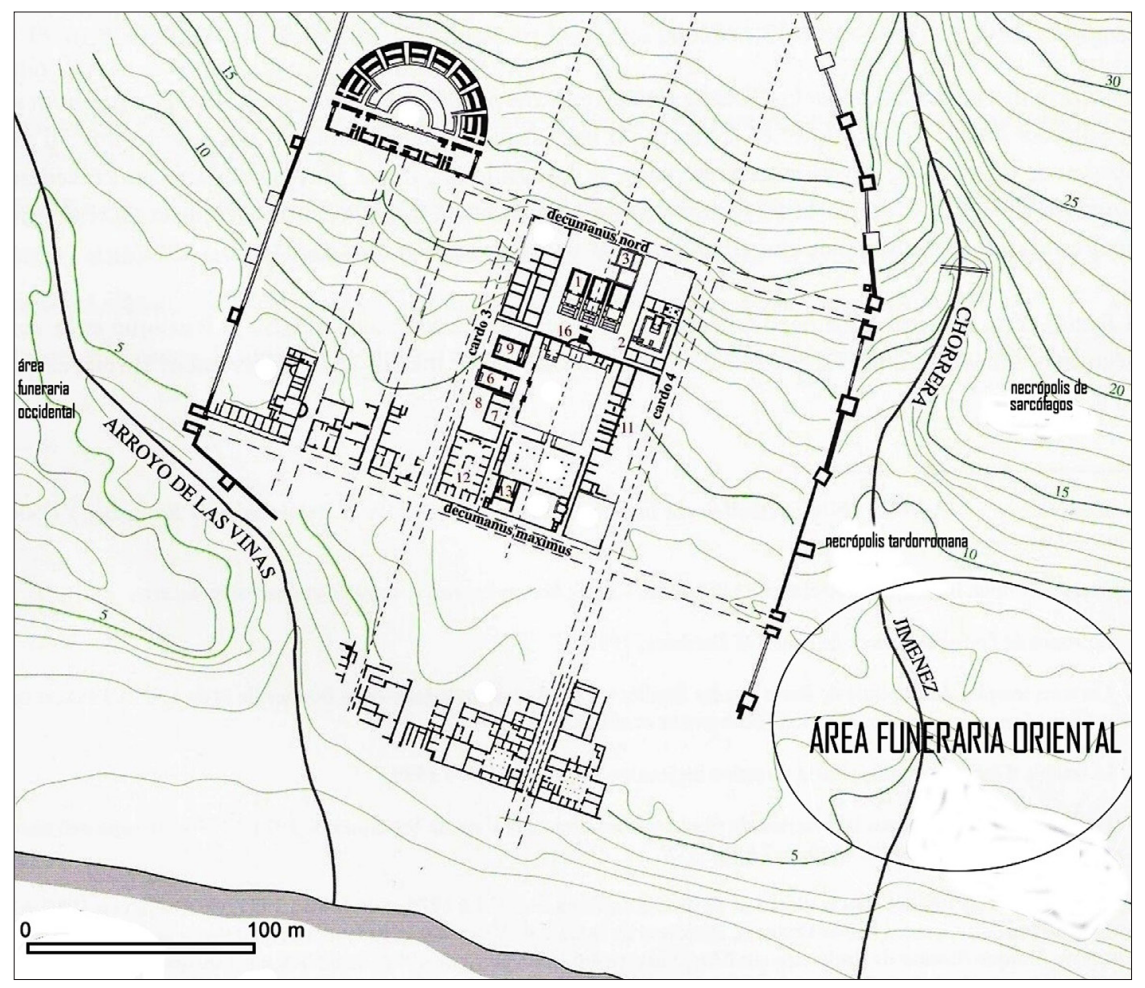

presencia de símbolos de estatus o rango, etc.) no tienen una misma lectura, de forma que hemos de observar si en la muerte se mantienen los mismos niveles de diferenciación social que en la vida, y cómo se expresan éstos en el registro funerario. Por ejemplo, la inversión de trabajo en la construcción de grandes monumentos funerarios, la celebración de ritos complejos, o la introducción de objetos exóticos o de difícil consecución en los ajuares, son considerados como indicadores de estatus.

El aspecto territorial de la necrópolis, su ubicación en relación con el asentamiento o la distribución interna de las propias tumbas, son también indicadores interesantes desde el punto de vista de la organización social. Pensamos que las diferencias sociales y económicas (y quizás étnicas que se intuyen) de la sociedad baelonense quedaron perfectamente reflejadas en la necrópolis y en los distintos tipos de enterramientos. El área sacra fue la misma para todos, pero la ubicación del sepulcro dentro de ésta y el tipo de monumento a erigir, variaron notoriamente en función del poder adquisitivo y de la ideología.

En el ámbito cultural romano, en torno al cambio de Era, se empieza a observar una articulación del espacio funerario propia y característica (en torno a las vías que abandonaban la ciudad y en recintos que parcelan el terreno dedicado a estos fines), dada la aparición de necesidades antes inexistentes como la identificación nominal de las sepulturas a través de los epígrafes, de las lápidas funerarias, o el empleo de monumentos que presentan tipologías similares a los que podemos encontrar en Italia. El problema principal es que esta cuestión, casi una norma para el resto de las provincias del Imperio, no sirve en algunos lugares donde se detecta una clara perduración cultural e ideológica púnica, caso de las necrópolis de Sabratha (Libia) Tipasa (Argelia) o, mucho más cerca, en Carmona (Sevilla) o la propia Baelo Claudia. Si revisamos y clasificamos los monumentos funerarios, se puede observar la existencia de, al menos, tres niveles de jerarquización en la necrópolis, que pueden tener correspondencia con la propia estructuración social -o étnica-, en función de la monumentalización arquitectónica, de la riqueza de los ajuares exhumados, de la ritualidad y de su posición respecto a la vía principal de comunicación:

Nivel 1: Se trata de los mausoleos ubicados junto a la puerta de Carteia, que son los que mayor tamaño y complejidad arquitectónica presentan y que, por ello, se pueden vincular a la élite urbana. Por su posición preeminente, 


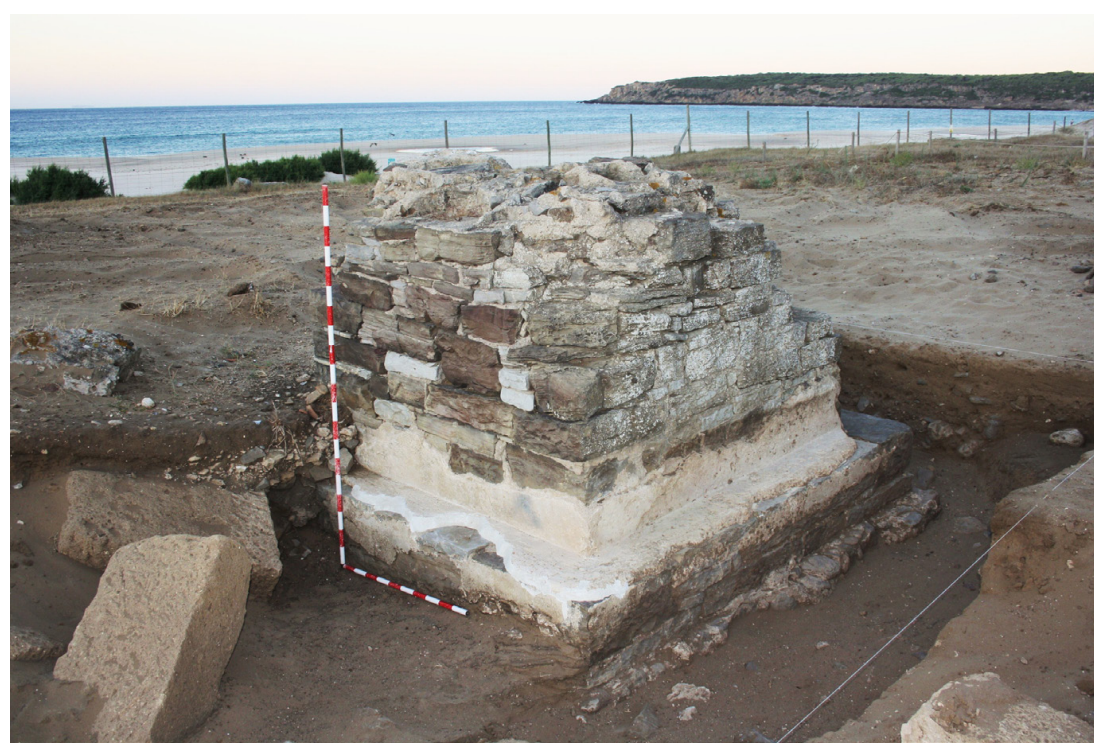

Fig. 4. El Hornillo de Santa Catalina re-excavado en 2010 .

junto a la puerta, deberían de ser los más antiguos. Se conservan dos monumentos realizados con sillares de calcarenita de época altoimperial y algunos sepulcros menores de inhumación, de carácter intrusivo y de cronología posterior. A falta de efectuar excavaciones, la reciente prospección geofísica desarrollada en otoño de 2013 bajo el aparcamiento próximo, refleja la continuidad del decumanus jalonado por sepulcros de entidad, hasta al menos $100 \mathrm{~m}$ de distancia de la puerta de la ciudad.

Nivel 2A: Se observa en un espacio funerario donde las tumbas de mayor y menor riqueza se ubican unas junto a otras desordenadamente. Es en este nivel donde se percibe un patrón funerario similar al púnico, siendo además donde se concentra la aparición de las célebres tallas antropomorfas (Remesal 1979: 46). Se trata de un conjunto de tumbas que fue fechado por J. Remesal en época claudia y los materiales estudiados por nosotros a partir de las limpiezas y la excavación de 2012 así lo ratifican. Este nivel " $2 \mathrm{~A}$ " se caracteriza por la existencia de una serie de sepulcros de mayor riqueza constructiva que presentan alrededor otros menores, remarcando una especie de jerarquización interna. Tipológicamente destacan los recintos dobles, compuestos de ustrinum y cámara decorada con pinturas y también se documentan los monumentos turriformes, entre ellos el llamado Hornillo de Santa Catalina (fig. 4). Podemos relacionar estos sepulcros con élites locales entre las que tendría bastante arraigo la tradición religiosa y cultural previa, que podríamos denominar "neopúnica".
Nivel 2B: Visible en el área de sepulcros ubicados junto a la playa. Aquí aparecen unos edificios que responden a patrones arquitectónicos de tipo itálico, cronológicamente más tardíos (finales s. I y s. II), destacando los edículos sobre podio, un columbario y varios monumentos de tipo templiforme. Aquí sí se observa la existencia de una organización y una jerarquización del espacio, respondiendo a nuevos criterios que, muy posiblemente, ya están instaurados en el marco de las relaciones sociales urbanas. Los nuevos edificios generan espacios arquitectónicos internos, siguiendo un patrón y unas necesidades rituales propiamente romanas (Vaquerizo 2011: 193) y se encuentran organizados en diverticula o calles, presentando, además, unas dimensiones in fronte e in agro similares (es decir, con unas medidas tanto de fachada como de fondo casi idénticas) aunque sin indicatio pedaturae. Topográficamente, los monumentos siguen una misma curva de nivel y su disposición alineada conforma una via sepulchralis que va girando levemente hacia el N, en dirección a la puerta de la ciudad. Vinculamos estos sepulcros con grupos exógenos arribados a partir de la municipalización de la ciudad a mediados del s. I y con las nuevas élites locales altamente romanizadas desde el s. II.

Nivel 3: Entre los sepulcros menores (cremaciones en urnas cerámicas y cajas de piedra, con o sin señalización exterior) podemos reconocer tumbas de pescadores y artesanos y, en algún caso, quizás libertos o esclavos que aparecen enterrados junto a los recintos dobles (siempre al exterior). Se ubican en torno a los sepulcros del nivel "2B". 
Veremos después como este nivel de jerarquización se relaciona estratigráficamente con la fase más antigua de uso del espacio funerario, a tenor de la secuencia obtenida en la excavación de 2012.

\section{EL ÁREA CENTRAL DE LA NECRÓPOLIS. EL HORNILLO DE SANTA CATALINA Y LOS RECINTOS DOBLES}

Uno de los primeros elementos que queremos valorar en esta área central es la presencia de una tipología de enterramientos en la que podemos vislumbrar la influencia del mundo funerario púnico. El caso más destacado es el de los sepulcros turriformes, macizos y que podemos relacionar con los clásicos tipos generalizados por todo el $\mathrm{N}$ de África y en Gades. El mejor conservado es el Hornillo de Santa Catalina. El llamado Hornillo es aparentemente cenotáfico y ocupa una posición central en la zona excavada. Se encuentra separado de la muralla oriental de la ciudad y de la llamada Puerta de Carteia por 188 m. Esta posición central -artificial- se explica porque supuso un elemento fundamental de referencia en las excavaciones antiguas, debido a su, por entonces, buena conservación. Se trata de un monumento funerario de tipo turriforme, de tamaño mediano (de unos 5,04 $\mathrm{m}^{2}$ de área máxima), completamente macizo en sus dos primeros cuerpos y con un nicho en el tercer cuerpo, que está rematado por una cubierta piramidal hoy destruida, pero aún visible y en pie en las fotografías tomadas por J. Bonsor entre 1917 y 1920.
El cuerpo inferior está realizado con mampostería regular, una especie de opus vittatum posiblemente de tradición republicana visible en otras construcciones de la ciudad, que usan mayoritariamente, como aquí, la roca arenisca. Este zócalo tiene unas dimensiones de 2,27 por 2,39 $\mathrm{m}$ de lado, por 0,29 $\mathrm{m}$ de anchura (que es la que sobresalió del monumento) y $0,70 \mathrm{~m}$ de altura (incluyendo una pequeña zapata de cimentación de unos $30 \mathrm{~cm}$ de potencia, enterrada bajo el suelo). Durante la re-excavación de 2010 se pudo documentar un intento de expolio en su cara occidental, con varias hiladas destruidas hasta la zapata. El expolio se detuvo al comprobar, tras penetrar $60 \mathrm{~cm}$ en el núcleo del basamento, que se trataba de una estructura completamente maciza y que, por tanto, no existía cámara sepulcral. Un dato relevante es que la perforación aparece sellada con un nivel arqueológico que, por los materiales (cerámicos y numismáticos), podemos fechar entre los ss. XIIIXIV y que permiten concretar, en ese momento o poco antes, el intento de expolio. La parte visible de este cuerpo inferior, que funcionó como podium, estuvo estucada y pintada en tonos negros y rojos, hoy mal conservados, que dibujan líneas figurando molduras arquitectónicas (fig. 4).

El segundo cuerpo está realizado con la misma técnica constructiva que el primero y se encuentra recubierto también por un estucado realizado en tres capas superpuestas, desde la más tosca a la exterior mucho más fina y cuidada, de la que quedan restos de pintura rojiza muy

Fig. 5. Planta y alzados del Hornillo de Santa Catalina realizados a partir de Photomodeler.

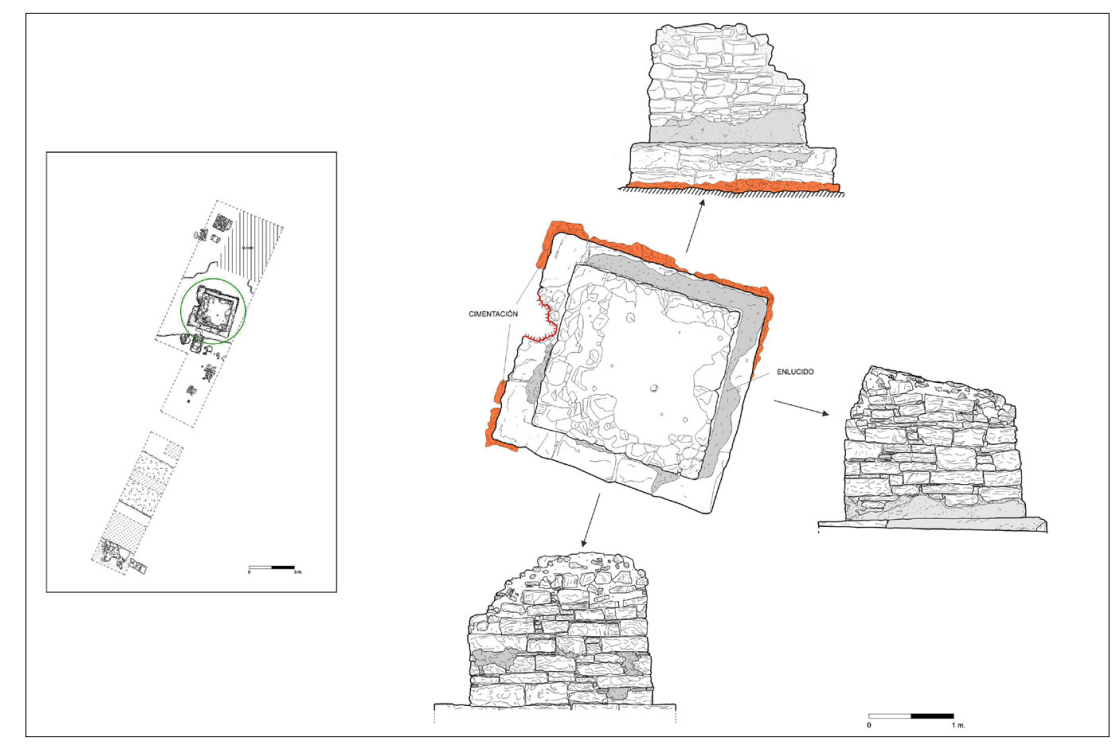


alterados. El cuerpo central tiene unas dimensiones irregulares $(1,96 \mathrm{~m}$ en el lado O por 2,08 $\mathrm{m}$ en el N, 1,97 m en el E y 2,10 m en el S). Presenta, a su vez, 1,90 m de altura máxima conservada (fig. 5).

La generalización del estucado de los monumentos funerarios, tratando de ocultar la pobreza de los materiales empleados en su construcción, es bastante frecuente en necrópolis romanas del área norteafricana y de Cádiz, con las que, tanto por afinidad cultural como por cercanía geográfica, relacionamos la de Baelo. La propia estructura maciza del monumento y el hecho de no señalar la ubicación de ninguna tumba debajo, lo vincula claramente con los monumentos funerarios de influencia semita -púnica- tan característicos de necrópolis en las que la tradición oriental se mezcla con la indígena en el momento del primer impacto romanizador, caso de las argelinas de Tipasa o las libias de Sabratha (Cintas 1949; Baradez 1957; 1968; Lancel 1968; 1970; Prados 2008; Prados y García 2009).

La limpieza superficial de la necrópolis y el estudio detallado del plano de J. Bonsor permitió localizar, a pesar de algunos errores de orientación detectados en el original, varios sepulcros enterrados por la sedimentación natural del último siglo. Se trata de los llamados recintos dobles (Sillières 1997: 194), que presentan una estructura cuadrangular realizada también en vittatum con sillares en las esquinas y con dos cámaras en el interior (el ustrinum donde fueron quemados los cadáveres y otro espacio de menor tamaño donde se guardaron las urnas con los restos de las cremaciones, fig. 11). Uno de los re-excavados ha sido identificado como la tumba IV del plano de J. Bonsor, también conocida como Tumba de las Guirnaldas por su decoración pictórica. El ustrinum de esta tumba, orientado al $\mathrm{N}$, aún presenta un enorme paquete de cenizas compactadas en su interior, que no hemos excavado, y la cámara funeraria, vaciada por $\mathrm{J}$. Bonsor, aparece estucada en blanco y con una decoración pintada de columnas jónicas unidas por guirnaldas tricolores (con tonos verdes, naranjas y rojos). En el interior de esta cámara había sido arrojada, ya en época antigua, un ara de calcarenita de $70 \mathrm{~cm}$ que había perdido la placa o soporte epigráfico. Ya J. Bonsor recoge en su dibujo de la Tumba de las Guirnaldas este hecho (Paris et al. 1926: 51 y fig. 34).

Los recintos dobles que acabamos de describir como depósitos funerarios son casi desconocidos en las necrópolis romanas (Sillières 1997: 195). Pese a ello, se encuentran modelos similares en Tiddis en el área argelina
(Février 1967; Berthier 2000) y en las necrópolis del área del Cabo Espartel, como Bou Kachkach, cerca de Tingis (Ponsich 1970), quizás éstas las más fáciles de emparentar con las de Baelo Claudia. También se documentan estructuras funerarias dobles en Volubilis, en un similar contexto socio-cultural (Jodin 1987). La estructura muraria externa delimita el espacio funerario, funcionando como el límite de una especie de temenos sagrado y el interior doble funciona como crematorio y tumba colectiva, posiblemente de carácter familiar. En las cámaras del interior, a $1 \mathrm{~m}$ aproximadamente de altura de la base, el recinto de delimitación suele presentar una muesca rehundida para encajar una cubierta que pudo ser de tegulae o madera. En todos los ejemplos nos encontramos ante unos tipos parece que de procedencia africana y que tienen posiblemente su origen en los recintos dobles prerromanos que se han excavado en algunos centros norteafricanos tales como Althiburos (Túnez). Un aspecto ritual que hemos podido documentar es que de las dos partes que componen los recintos dobles, la cámara sepulcral es siempre la más cercana a la zona de tránsito, mientras que el ustrinum aparece en la más alejada. La orientación de estos monumentos, por lo tanto, varía en función de la ubicación del recinto doble respecto de la vía.

\section{LA VIA SEPULCHRALIS MERIDIONAL}

Para la realización del levantamiento planimétrico se prospectó la zona con exhaustividad, tratando de localizar todos los restos de construcciones funerarias visibles en superficie y detectando los innumerables elementos conservados en posición secundaria de cara a su referenciación cartográfica. De la zona más próxima a la playa sólo fueron limpiados algunos monumentos funerarios para su documentación gráfica, no formando parte de las labores generales de limpieza y re-excavación anteriormente descritas para otros sectores.

A pesar de que aún no nos hemos centrado con detalle en esta zona meridional, gracias a la realización del levantamiento se pudo incluir un número mayor de monumentos funerarios y otros elementos tales como los soportes de estelas que amplían la visión general de la necrópolis y delimitan su extensión, facilitando, además, el análisis espacial y una mejor comprensión general. La estrategia de prospección adoptada durante nuestra intervención tuvo un carácter intensivo. El resultado ha sido un registro exhaustivo, tanto de la distribución de los elementos arquitectónicos como de sus características y 
estado de conservación. En la prospección, que se desarrolló en la campaña de 2009, se pretendió realizar una estimación de la densidad global de materiales en superficie. El objetivo de esta labor ha sido la de delimitar las áreas de mayor concentración de indicios. Igualmente, nos interesaba cartografiar las zonas con hallazgos en superficie así como las áreas completamente vacías de ítems, susceptibles de no haber sido intervenidas.

En una de estas zonas, al S del Hornillo de Santa Catalina, se planteó la excavación de una trinchera de delimitación, con unas dimensiones de $15 \mathrm{~m}$ de largo por 2,5 $\mathrm{m}$ de anchura. Consta de una estratigrafía sencilla con unidades horizontales sin apenas alteraciones que se explica porque todas fueron depositándose directamente sobre el pavimento de la vía funeraria principal. De hecho, el principal hallazgo de este corte es la aludida vía pavimentada, realizada con esquirlas de piedra hincadas sobre una cama arcillosa y compacta (rudus) con unas dimensiones de 3,70-4 $\mathrm{m}$ de anchura y un espesor de $30-40 \mathrm{~cm}$.

La disposición horizontal y homogénea de los distintos estratos, tanto aquéllos que relacionamos con el uso de la vía funeraria como los de génesis sedimentaria que cubren a éstos, apunta a que no han sido alterados por actuaciones posteriores y que han ido cubriendo paulatinamente una superficie compacta y horizontal como el pavimento de la calle. Uno de los datos a priori más interesantes es que este trazado pavimentado cubrió parcialmente restos de uso de la necrópolis en una fase previa. Igualmente, esta calle estaría relacionada con una reordenación del espacio funerario en la segunda mitad del s. I d.C., a tenor de los materiales arqueológicos asociados. Supone, asimismo, la organización de los sepulcros que se construyen junto a la playa (nivel de jerarquización "2B") y que tanto estratigráficamente como por su tipología o por sus materiales de construcción, relacionamos con la última fase de uso funerario de este sector de la necrópolis.

Sobre los monumentos de esta zona, al tenerlos visibles sólo en planta, apenas tenemos más datos que los ya referidos: tipológicamente responden a modelos más fácilmente identificables como romanos (templos-tumba, edículos, podios e incluso un edificio de gran tamaño que interpretamos como columbario), están realizados en roca calcarenita o caliza fosilífera y, sobre todo, presentan una organización espacial distinta, jalonando unos junto a otros la vía de acceso en paralelo a la costa, con las peculiaridades en su orientación que acaban de ser referidas en el párrafo anterior. También los materiales parecen algo posteriores, con una mayor presencia porcentual de TSH y, curiosamente, no aparecen cipos ni tallas antropomorfas, un hecho relevante que ya se ha apuntado y sobre el que volveremos.

Para concluir, cabe señalar que en la necrópolis oriental, a falta de precisar más en futuros estudios, se puede observar cómo los enterramientos más antiguos, (fechados desde finales del s. I a.C. hasta mediados del s. I d.C.) aparecen agrupados y se concentran en una zona de menores dimensiones que otros sepulcros de otras épocas que sí se reparten por un espacio mejor planificado, donde se detectan mejor los diverticula. Ya fue señalada por J. Remesal la agrupación de los distintos grupos de enterramientos en la necrópolis (Remesal 1979: 11). Este abigarramiento y cierto desorden de los sepulcros más antiguos recuerda mucho a las necrópolis púnicas y a las primeras afrorromanas que mantuvieron la misma tradición funeraria. Allí los cementerios se concentraron en puntos concretos, dentro de un espacio sagrado o temenos. También existen buenos paralelos en zonas más próximas, caso de Tingis o el Cabo Espartel en Marruecos, concretamente las necrópolis de Bou Kachkach y Marschan, con similares cronologías a ésta de Baelo (Ponsich 1970).

\section{UNA SECUENCIA ESTRATIGRÁFICA COMPLETA. LA EXCAVACIÓN DE 2012}

Hemos visto cómo hacia mediados del s. I se comienza a observar en la necrópolis una articulación del espacio funerario característicamente romana (jalonando las vías que abandonaban la ciudad y en áreas dedicadas a estos fines) y se observa la plasmación de necesidades antes inexistentes como la identificación nominal de las sepulturas a través de los epígrafes, de las lápidas funerarias, o del empleo de monumentos que presentan tipologías similares a los que podemos encontrar en otras provincias del Imperio. Esta nueva articulación del espacio pensamos que va unida a la construcción de la vía sepulcral detectada en la campaña de 2012 y que va a marcar la disposición de los sepulcros enclavados en la zona más próxima a la playa, todos ellos con la fachada situada al borde de la mencionada vía.

Ya hemos mencionado que se pudo excavar una trinchera de delimitación en sentido N-S de 15 m de longitud por 2,5 m de anchura (fig. 6). Esta trinchera atraviesa el área de intervención bajo una zona de terreras desmontadas mecánicamente en los últimos años. La existencia 


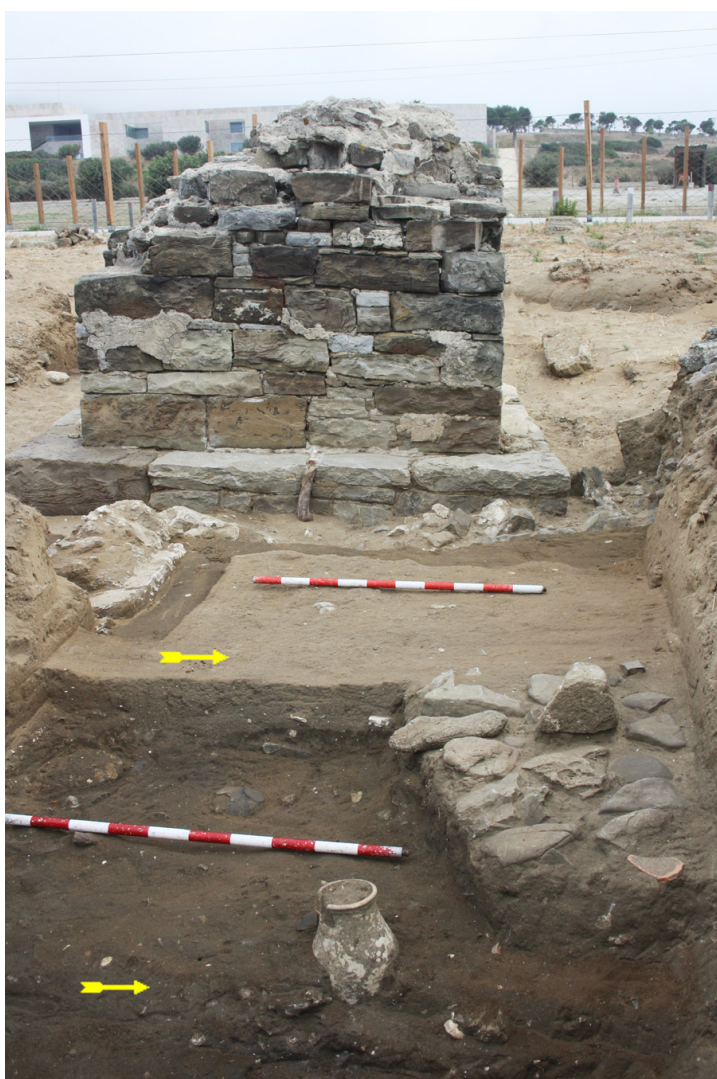

Fig. 6. Sepulcros de la fase Ia y Ib en la trinchera excavada en 2012 La flecha superior indica el nivel de circulación y la inferior, el de uso de la necrópolis.

de estas terreras, como hemos tenido ocasión de comentar, supone la potencial supervivencia en el subsuelo de pequeños sectores de la necrópolis que conserven estratigrafías útiles no alteradas por las excavaciones de principios del s. XX. Desde el punto de vista metodológico, se ha realizado esta excavación con la intención de buscar respuesta a algunas de las dudas planteadas en los últimos años: en primer lugar, de cara a la obtención de una secuencia estratigráfica general de este sector cementerial; en segundo lugar, para recuperar la topografía original; en tercer lugar, para constatar la existencia de zonas intactas en las que obtener secuencias puntuales que ayuden a establecer las cotas de los suelos de uso y de circulación de la necrópolis, y por último, con la intención de observar las relaciones estratigráficas entre los sepulcros del área central (de cronología claudio-neroniana) y los ubicados junto a la playa (fechados a final de la centuria).

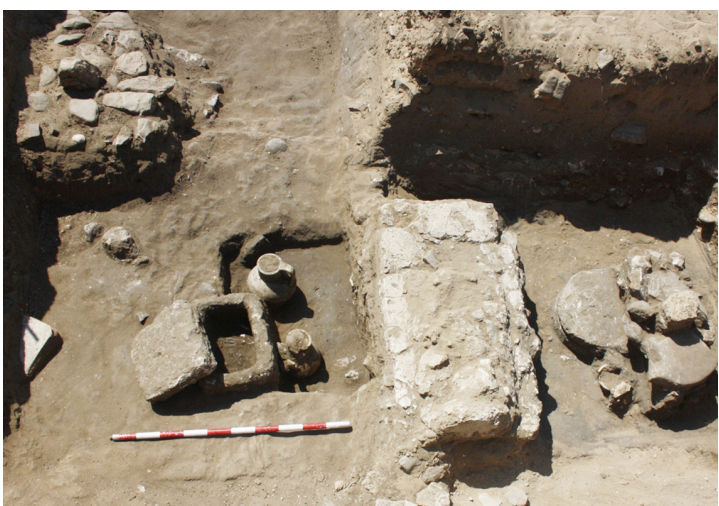

Fig. 7. Conjuntos funerarios D, C y B. En el centro, la cupa structilis.

La excavación de 2012 ha ofrecido nuevos e interesantes datos y ha cumplido los objetivos referidos. El éxito de la elección de este lugar para la realización de los sondeos no es casual y se debe a los trabajos previos de levantamiento de planimetrías durante las actividades puntuales de campañas anteriores $(2009,2010$ y 2011) y a la georreferenciación del plano elaborado por J. Bonsor entre 1917 y 1921, que apuntaba a que no hubo intervención en esta zona, como tuvimos la oportunidad de comprobar.

Ya hemos referido anteriormente la localización de la vía sepulcral como hecho destacado, por eso nos detendremos ahora en los sepulcros excavados correspondientes a las primeras fases del uso funerario en este sector. Durante las excavaciones e inmediatamente por debajo de los niveles superficiales de génesis sedimentaria y aporte eólico, aparecieron los primeros elementos marcadores de sepulcros, concretamente estelas de piedra que señalaban, como se pudo estudiar con detalle después, diversos conjuntos funerarios que agrupaban, en una misma fosa, asociaciones de urnas de piedra y jarras monoansadas de cerámica común (ollae ossuoriae), todos ellos contenedores de cenizas (fig. 7).

En total han sido excavados cuatro conjuntos funerarios (denominados A, B, C y D) y una cupa structilis (T2006) con la mesa de ofrendas conservada (fig. 8), que pertenece a una fase algo posterior, pues su construcción rompe los niveles de enterramiento de dos de los conjuntos funerarios previos (en concreto los conjuntos C y D). Esta cupa albergaba varias urnas cerámicas cubiertas con platos como deposiciones funerarias de uno o varios individuos. Los conjuntos aparecen bajo estructuras irregulares con pequeñas estelas que sobresalen (como único elemento visible). Por debajo se documentan urnas de 
calcarenita de sección cuadrangular o cilíndrica con tapa y dos o tres jarras monoansadas de cerámica común. Las fosas en las que se colocaron estas urnas aparecen rellenadas con tierra y cenizas.

Dentro de estos depósitos aparecen elementos de ajuar como un acus crinalis de hueso, un espejo de bronce, fíbulas, un porta-amuletos para guardar sustancias aromáticas y varias monedas (numerario de Carmo y de Carteia). Cabe reseñar que aunque aparece un clavo de bronce retorcido junto a cada una de las deposiciones, sólo hemos documentado una moneda por cada conjunto funerario. Pensamos que cada clavo fue ubicado ex profeso con la intención de fijar el alma del difunto a la tierra, señal del tránsito sin retorno que supuso la muerte (Alfayé 2009: 190; Vaquerizo 2010: 41). En cambio, al encontrar una moneda por conjunto funerario y no por sepulcro, no consideramos que se trate de óbolos (para el pago ritual al barquero Caronte que conllevaría una moneda por deposición funeraria siguiendo el rito grecorromano) y sí más de elementos de protección o profilaxis, aspecto éste señalado recientemente para la necrópolis de Cádiz y que se relaciona con una religiosidad de tipo púnico (Arévalo 2010: 517). Además, no parece casual que se usasen monedas antiguas, casi reliquias, como amuletos, y que éstas se caractericen por presentar en sus tipos una iconografía vinculada de forma recurrente con el dios MelkartHércules, indicando, quizás, un tipo de culto específico dentro de este ambiente funerario.

Dejando para otra ocasión la descripción de los conjuntos y las tumbas, para no alargar en demasía este artículo, pasaremos a presentar una lectura sintética en la que se referirán las diferentes fases que se han documentado a partir de la excavación y la lectura estratigráfica arrancando desde la más antigua (ver sección en fig. 8):
Fig. 8. Planta de los diversos conjuntos funerarios excavados en 2012, al S del Hornillo de Santa Catalina.

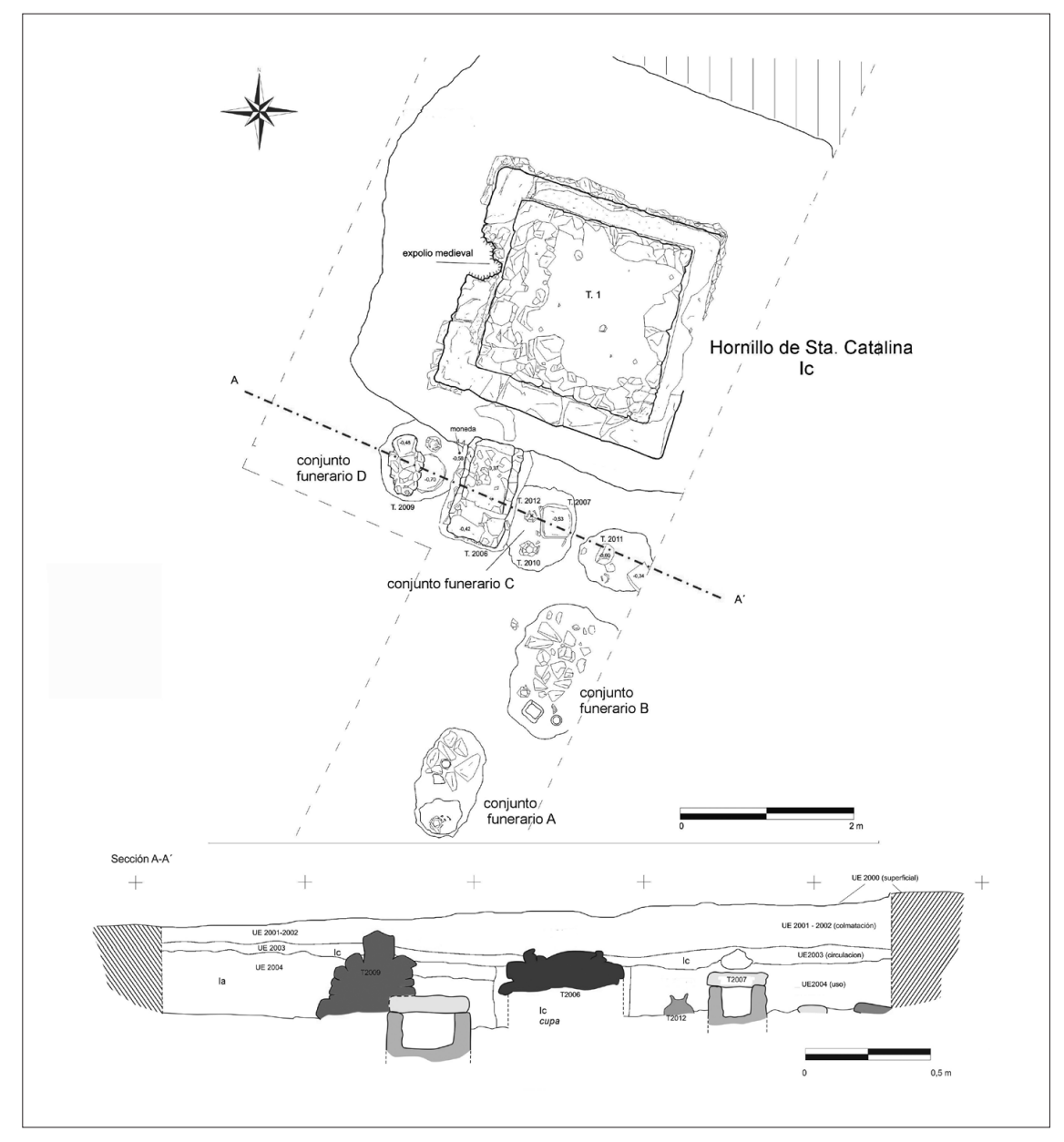


Fase Ia: que reconocemos por los conjuntos funerarios señalados con cipos o estelas de piedra muy toscas que delimitan fosas en las que aparecen distintas cremaciones. Esta fase está caracterizada por el uso del espacio funerario mediante la deposición de cremaciones en jarras de cerámica cubiertas con platos, con restos del ritual (platos y copas de TS fragmentados) en el entorno, junto a cajas de piedra de formas y tamaños diversos (paralelepipédicas o cilíndricas). Podemos fechar estas deposiciones hacia el cambio de Era o ya en las primeras décadas del s. I d.C.

En el conjunto funerario $\mathrm{C}$ apareció una única moneda, que relacionamos más con un amuleto que con un óbolo, por lo que se ha comentado anteriormente. En este caso se trata de un semis de Carteia con cabeza torreada a derecha en el anverso y la leyenda CARTEIA. En el reverso aparece Neptuno mirando a la izquierda con la pierna derecha alzada sobre una roca, la mano izquierda

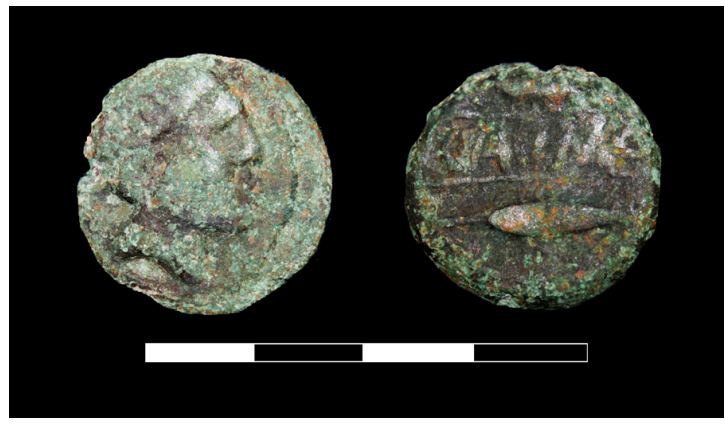

Fig.9. As de Carmo acuñado a principios del s. I a.C. localizado en el Conjunto funerario $\mathrm{C}$. portando un tridente y la derecha con delfín y la leyenda D.D. Según los especialistas se trata de la $29^{\text {a }}$ emisión de la ciudad, fechada a finales del s. I a.C. o principios del I d.C. (Chaves 1979: 151-156).

El Conjunto Funerario D ofreció, por su parte, datos de enorme relevancia acerca del ritual funerario y de la deposición de los distintos elementos. En este caso, se ubicaron sendas cremaciones en una urna circular y en una jarra monoansada de cerámica común respectivamente. Ambos elementos, que contenían ceniza en su interior, fueron colocados en una fosa circular en la que únicamente se documentó una moneda de Carmo de principios del s. I a.C., que debió funcionar de nuevo como una especie de amuleto (fig. 9). Cabe subrayar la inclusión de esta moneda en un sepulcro que, a tenor del resto de los materiales arqueológicos (TSG), debió realizarse en las primeras décadas de la Era, es decir, al menos un siglo después de su acuñación. Posteriormente, este conjunto de urna cerámica y caja de calcarenita fue cubierto con tierra, se colocó un clavo de hierro y se cubrió después. Sobre las piedras se colocó un cipo vertical señalizando todo el conjunto funerario, siendo el único elemento exterior visible. Entre estas piedras, fragmentados y posiblemente rotos sobre ellas, aparecieron fragmentos de vasos de paredes finas y de TSG, que pudieron emplearse en algún rito de libación. Cabe apuntar que estos elementos cerámicos fueron amortizados durante el proceso mismo de enterramiento y que fueron cubiertos con piedras y el cipo.

Fase Ib: en la que se edificaron los recintos funerarios dobles ya descritos, amortizando algunas tumbas de la primera fase (hecho relevante para establecer la secuencia temporal). En esta fase se erige el monumento

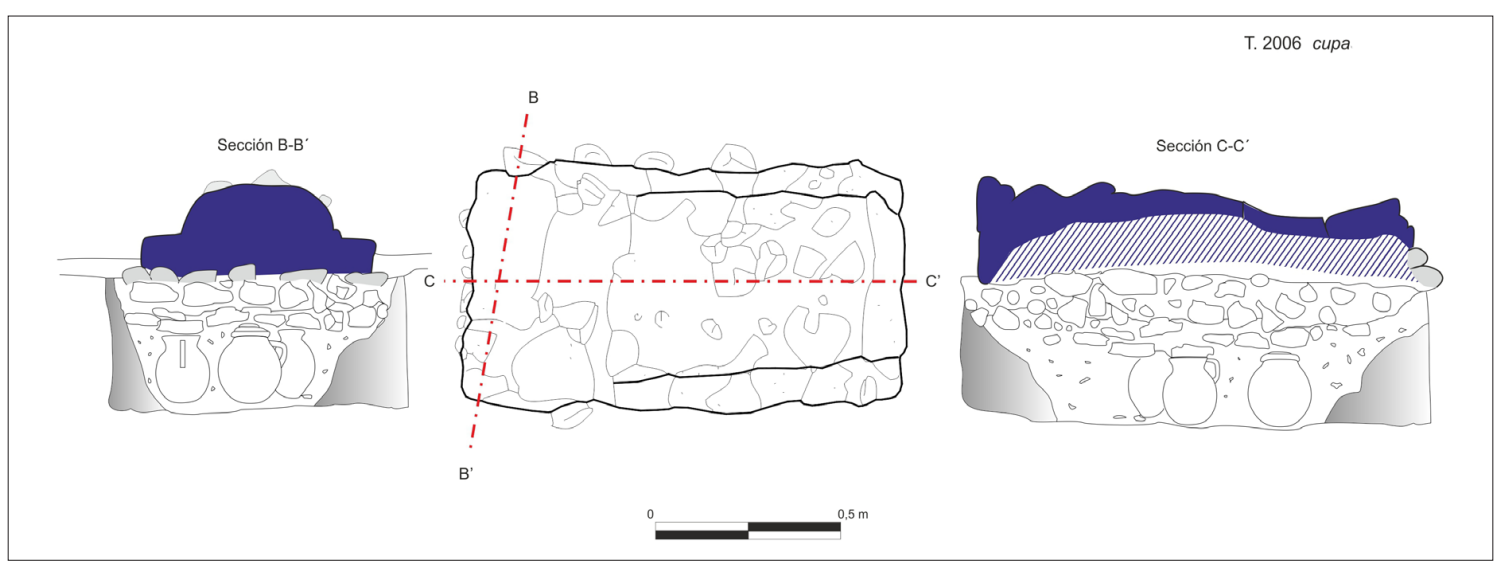

Fig. 10. Planta y sección de la cupa T-2006. 


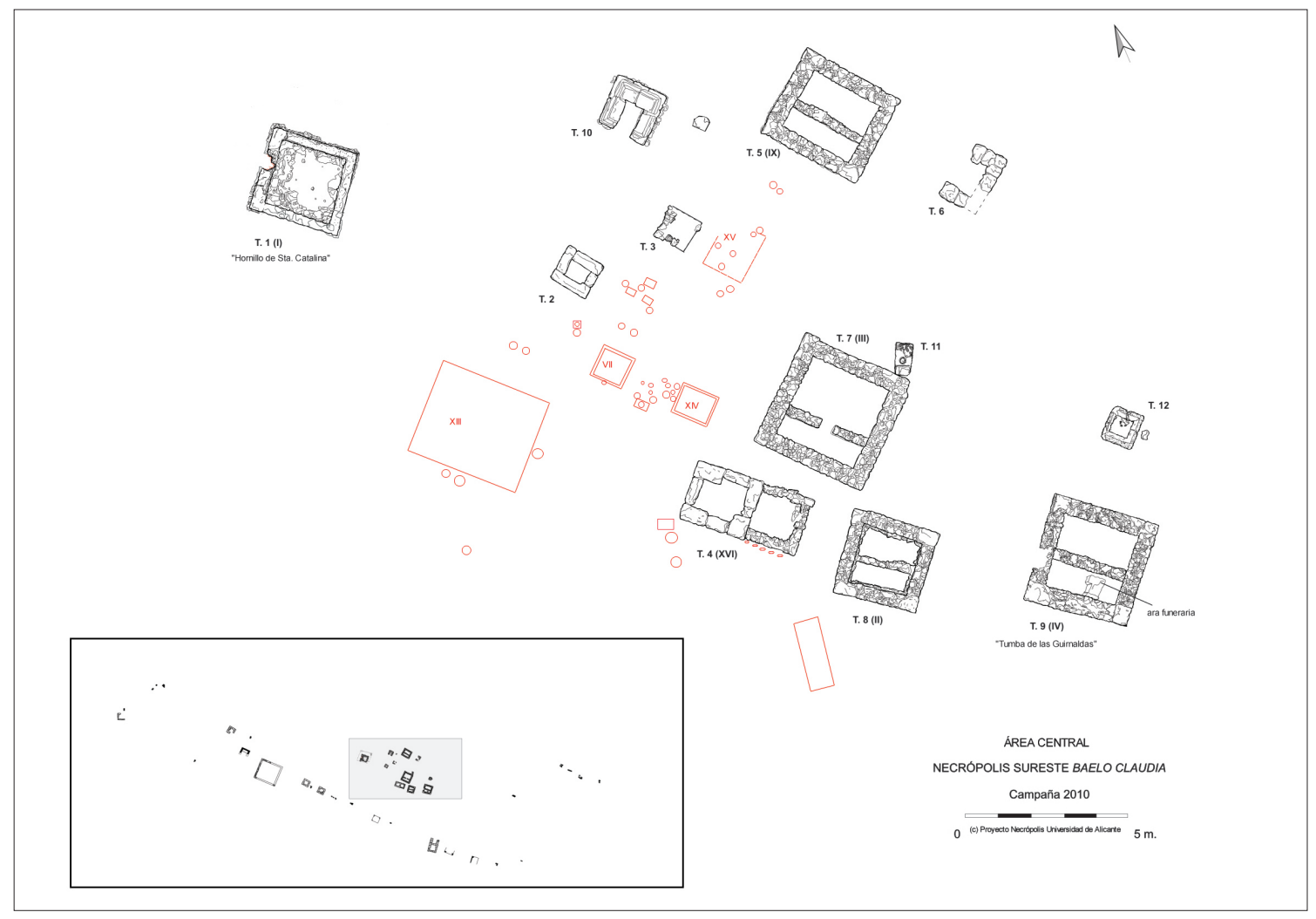

Fig. 11. Planta del área central de la necrópolis integrando los sepulcros hoy no conservados dibujados por Bonsor.

turriforme Hornillo de Santa Catalina. Estos sepulcros generan cierto orden y se pueden fechar, a tenor de los materiales obtenidos (numerario de Claudio, TSI, TSG, TSH, ánforas Dressel 7/11, etc.) hasta mediados del s. I.

Fase Ic: cuando se erigen otros sepulcros hacia mediados del s. I. A este momento pertenece la construcción de la cupa structilis documentada (fig. 10), cuya cimentación corta los niveles de uso de la necrópolis en sus Fases Ia y Ib (fig. 8). Se trata de uno de los primeros ejemplares de este tipo de enterramiento en el área costera de la Bética y parece confirmar algunas de las hipótesis esgrimidas en este sentido por los especialistas sobre la introducción del sepulcro tipo cupa por el estrecho de Gibraltar desde el N de África (Julia 1965: 51; Baratta, 2006: 1673; Vaquerizo 2010: 303; Tupman, 2012: 11).

Fase II: esta fase se define por la remodelación y reordenación de todo el espacio funerario oriental, coincidente con las actuaciones detectadas en otros ámbitos urbanos que se relacionan con el nuevo estatuto de municipio en la ciudad. Se detecta la construcción de una vía pavimentada con un rudus elaborado con cantos y esquirlas de piedra colocadas de forma irregular sobre una cama preparatoria arcillosa muy compacta. Esta vía funeraria mide unos $4 \mathrm{~m}$ de anchura y cubre los niveles de uso de la necrópolis en su Fase I. Cabe remarcar que desde la segunda mitad del s. I se detectan cambios importantes en otros sectores de la ciudad coincidentes con el nuevo estatuto de municipio que debió traer consigo aportes de población (Sillières 1997). Quizás a esta nueva generación podamos vincular la reordenación del espacio funerario, la construcción de la vía y los monumentos que referiremos en la Fase III. En el nivel preparatorio de construcción de la vía se documentó un hallazgo significativo: se trata de un As de Claudio que ofrece una clara datación post quem.

Fase III: en la que se construyen sepulcros junto a la playa que responden a patrones arquitectónicos de tipo itálico como se ha comentado. En esta fase, que ponemos en relación con el nivel de jerarquización " $2 \mathrm{~B}$ ", se observa que están instaurados ya patrones romanizados. Los materiales arqueológicos recogidos parecen algo posteriores, 
con una mayor presencia porcentual de TSH y, curiosamente, no aparecen cipos ni tallas antropomorfas como en la Fase I. Ello quizás se explique por la hipótesis que hemos apuntado anteriormente: estos monumentos se ponen en relación con los nuevos grupos venidos de fuera hacia mediados de la centuria, en relación con la municipalidad (Padilla 2010). La nueva élite comenzará a ocupar este sector funerario a partir del último cuarto del s. I, jalonando la nueva vía que había reestructurado la necrópolis (fig. 11).

Fase IV: debido a la presencia de materiales cerámicos de tradición meriní y numismática medieval en los contextos superficiales, hemos de señalar un uso de este espacio a lo largo de los ss. XIII y XIV. Éste se detecta, sobre todo, en el entorno del Hornillo de Santa Catalina y quizá tenga que ver con intentos de expolio del que debía ser el monumento funerario más llamativo. La aparición de numerario medieval, concretamente de un cornado de vellón de Sancho IV (Prados et al. 2013) y diversas picas de hierro en superficie, podrían relacionarse con un episodio histórico fundamental en la zona como es la conquista de la plaza de Tarifa en 1292 y con la existencia de un campamento militar castellano en la Ensenada de Bolonia, quizás albergado intramuros de la propia ciudad hispanorromana. Es llamativo que estos contextos no hayan sido localizados (o tenidos en cuenta) en otros sectores de una ciudad profusamente excavada desde principios del s. XX, y que han generalizado la idea de que se abandonó definitivamente en el s. VII (Sillières 1997: 63).

Fase V: correspondiente con las excavaciones de P. Paris y J. Bonsor (Paris et al. 1926) se han detectado durante la excavación remociones de niveles arqueológicos, vaciado de sepulcros y constatación de estratigrafías invertidas junto a monedas y otros materiales de principios del s. XX. A esta última fase podríamos incorporar las fosas de expolio de sillares y otros elementos pétreos para la construcción de la carretera y de otras edificaciones del viejo poblado de Bolonia.

\section{CONSIDERACIONES FINALES}

Gracias al estudio de los antiguos informes y a la revisión de la documentación arqueológica archivada se han podido unificar datos dispersos que no habían sido puestos en común hasta el momento y que están apoyados en nuevas y más completas planimetrías (Prados 2011: 196). Bien es cierto que la necrópolis oriental de Baelo había sido objeto de diversas publicaciones, aunque la mayor parte se habían centrado, únicamente, en el análisis de los datos extraídos de determinadas campañas de excavación (Paris et al. 1926; Mergelina 1927; García y Bellido y Nony 1969; Bourgeois y del Amo 1970; Remesal 1979) o en otros aspectos más precisos vinculados con elementos materiales o problemas científicos concretos, como la adscripción cultural de los célebres cipos o muñecos (entre otros: Vaquerizo 2006 o Jiménez 2007).

Las labores en curso están permitiendo la definición de espacios y usos funerarios y la determinación de potenciales áreas de jerarquización social -y puede que cultural o étnica-. De este modo se podrán conocer las costumbres y las prácticas religiosas, observar y estudiar la riqueza de los sepulcros y los ajuares o rituales, además de tratar de definir aquéllos pertenecientes a las primeras fases de ocupación de la ciudad a finales del s. II a.C., aún pendientes de especificar. Por otra parte, futuras actuaciones permitirán la definición de las diferentes identidades así como la tradición nativa y los potenciales aportes de elementos demográficos africanos en primer lugar o itálicos después.

También hemos de tener en cuenta el gran desconocimiento, en general, del mundo funerario de época republicana que, sin lugar a dudas, daría luz sobre el discutido tema de las perduraciones púnicas. Sí se han detectado manifestaciones relacionadas con la matriz africana en contextos funerarios béticos como los de Carissa Aurelia, Carmo, quizás Corduba y, por supuesto, Baelo Claudia (García-Bellido y Blázquez 2001; Bendala 2006; Jiménez 2008). Si bien es éste un aspecto que se encuentra en el centro de un interesante debate (Vaquerizo 2006: 319).

En cualquier caso, hay que valorar la importancia del registro arqueológico funerario como fuente de investigación histórica, si bien teniendo presente los problemas metodológicos derivados de la falta de publicación, de estudio de materiales o de pérdida de datos tras las excavaciones antiguas. Además, se ha de partir de un hecho obvio pero frecuentemente olvidado: se trata de la necrópolis de una ciudad no romana inicialmente, aunque su romanización fue evidente. En nuestra opinión, Baelo experimentó un proceso urbanístico bastante repetido en el que el núcleo originario, situado con bastante probabilidad en el oppidum de la Silla del Papa (Moret et al. 2008 y 2010) se trasladó a la costa para convertir en centro urbano principal lo que en principio debió de ser un pequeño asentamiento costero (Bendala 2006; 2010; Prados et al. 2012). 
Los resultados de futuros trabajos como los ya emprendidos sobre la necrópolis de la Silla del Papa por el equipo franco-español de la Université de Toulouse y los aquí firmantes serán fundamentales en este sentido. Todo apunta a que Baelo se convirtió en un municipio de derecho latino bajo Augusto, quien debió potenciar las actividades pesqueras salazoneras estimulando el abandono del oppidum de la Silla del Papa, trasladando la población al asentamiento costero (Padilla 2010: 202) y arrancando, de este modo, el proceso de urbanización y monumentalización de la ciudad. Como tal quedó englobada en el seno del Imperio e inmersa en un proceso de progresiva intervención de élites itálicas o romanas, que comenzaron a ocupar paulatinamente las necrópolis, según hemos detectado.

Hemos de tener presente que el trasiego de población entre ambas orillas del Estrecho debió de ser constante y este flujo debió de reflejarse en las necrópolis. Pensemos en pescadores temporeros que faenaron, sin duda, en ambos lados del Fretum en función de la ubicación de los bancos de pesca o de las almadrabas. Por otro lado, aparte de las constantes referencias textuales al paso del Estrecho por esta zona, como la célebre de Estrabón que menciona que tras Mellaria están la ciudad y el río de Belon. Belon es el puerto donde generalmente se embarca hasta Tingis, en Maurusia (Estrabón, Geo., III, 1, 8) o las alusiones de los itinerarios, se ha de tener presente que, además de padecer constantes razzias mauri (Villaverde 2011: 47) Baelo debió de cobijar a gentes procedentes de la Tingitana en momentos de inestabilidad, algunos acreditados históricamente como la revuelta de Aedemón tras el asesinato de Ptolomeo. La muerte del último rey mauritano fue ordenada por Calígula (hacia el año 40), poco antes de la instauración de la Provincia Mauretania. Entre las élites residentes en los centros urbanos más importantes como Tingis o Volubilis se apostó por la romanidad, como se observa en la epigrafía (Christol 1985), mientras que en el campo o en otros centros secundarios se mantuvo firme una resistencia a Roma. Es cierto que este concepto de resistencia está siendo etiquetado actualmente como colonial y se encuentra en revisión (p.e. Jiménez 2007b: 24), pero nos basamos en la documentación estrictamente arqueológica y epigráfica (Prados et al. 2012).

Si tenemos en cuenta que en esa misma década Baelo adquirió su estatuto de derecho romano, otorgado por Claudio, quizás debamos suponer que, por su posición geoestratégica, jugó un papel decisivo en los conflictos y revueltas acaecidas en el Fretum Herculeum. Claudio hubo de premiar, de alguna forma, la colaboración de
Baelo en los conflictos que Roma tenía con el N de África. Esta ciudad debió de ser clave para, entre otras cosas, aprovisionar los ejércitos que pacificaron Mauretania y que tuvo como consecuencia no sólo su promoción jurídica, sino también la de otros centros urbanos principales de la región como Tingis, Lixus y Volubilis (Padilla 2010: 203). Por otra parte, sabemos por las fuentes que era algo habitual realizar traslados de población africana al territorio hispano. Un ejemplo bien atestiguado es el de la fundación de ciudades en la orilla hispana del Estrecho, si bien algo anteriores en el tiempo, como Iulia Traducta o Iulia Ioza (=trasladada) o Tingetera (=Tingis altera) y en la que debieron de ser trasladados africanos, a la par que llegaron nuevos colonos itálicos o procedentes de otros lugares de la Bética (Estrabón, Geo., III, 1, 8; Mela, Chor., II, 5, 96; Plinio, N.H., V, 1; Dion Casio, Hist. Rom., XLVIII, 45, 3).

La presencia de estas élites se puede entender por la importancia de la ciudad en el control de un sector estratégico principal en la pujante economía del Imperio, representado por la pesca y las industrias del pescado. Como se ha dicho, parece que a partir de Augusto adquirió la ciudad los privilegios del derecho latino (Wiegels 1985: 20) como oppidum latinum, y la plena ciudadanía, como municipium civium romanorum desde época de Claudio, según acreditan los escasos epígrafes hallados en la ciudad. Pero es su carácter de ciudad púnica, progresivamente romanizada jurídica y culturalmente, el que ha de tenerse en cuenta para estudiar su centro cívico y religioso (Bendala 2010) y, claro está, sus necrópolis (Prados 2011).

Según los estudios onomásticos y antroponímicos realizados, en la ciudad de Baelo se documenta un creciente proceso de consolidación de élites foráneas, sobre todo a partir de la segunda mitad del s. I e inicios del II (Padilla 2010: 194). Se trató de oligarquías de distinta procedencia (Cornelius, Pupius, Sempronius, Vecilius, Manilius...), puede que parte de ellas de origen local. También se ha documentado la existencia de una sólida base demográfica norteafricana (Lefebvre 2006: 139 y ss.; López Castro y Belmonte 2012: 150) con algunos cognomina procedentes de traducciones púnicas (Honoratus, Novellus, Optatus, Rufus y Saturninus). Curiosamente, ha sido la epigrafía funeraria la que ha permitido documentar la presencia de estos grupos de norteafricanos entre los sepultados en la necrópolis oriental (Bonneville et al. 1988: no 34 y 36; Sanmartín 1994: 244; Padilla 2010: 200) dato que consideramos clave para ratificar lo aquí expuesto. 
La amplia y sólida presencia de componentes demográficos africanos, clave para comprender las peculiaridades de la necrópolis oriental, pensamos que se ha de explicar por el desarrollo de la industria conservera, que debió de necesitar, lógicamente, una amplísima mano de obra, tanto para desarrollar las actividades pesqueras como para la manufactura industrial. Ya M. Ponsich, buen conocedor de las actividades económicas $-\mathrm{y}$ de las necrópolis en una y otra orilla del Estrecho- señalaba que entre estos africanos mencionados en la epigrafía funeraria destacaban los especialistas en la pesca del atún (Ponsich 1988: 92-99). Sirva esta última cita de homenaje a quien siempre supo mirar Baelo con Tánger como telón de fondo.

Fernando Prados Martínez Depto. de Prehistoria, Arqueología, $\mathrm{H}^{\mathrm{a}}$ Antigua Filología Griega y Filología Latina Universidad de Alicante fernando.prados@ua.es

IVÁN GARCÍA JiMÉNEZ Conjunto Arqueológico de Baelo Claudia Junta de Andalucía ivan.garcia@juntadeandalucia.es

Helena Jiménez Vialás Depto. de Prehistoria y Arqueología Universidad Autónoma de Madrid helena.jimenez@uam.es

\section{BIBLIOGRAFÍA}

ALFAYÉ, S. (2009): Sit tibi terra gravis: magical-religious practices against Restless dead in the ancient world, Formae mortis: el tránsito de la vida a la muerte en las sociedades antiguas (F. Marco, F. Pina, J. Remesal, eds.), Barcelona, 181-205.

ARÉVALO, A. (2010): Monedas para el más allá. Un primer acercamiento desde la necrópolis de Cádiz, Las necrópolis de Cádiz. Homenaje a J .F. Sibón (A. Niveau, V. Gómez, coords.), Cádiz, 507-527.

ARÉVALO, A.; BERNAL, D.; MUÑOZ, Á.; GARCÍA, I; MACÍAS, M. M. (2006): El mundo funerario tardorromano en Baelo Claudia. Novedades de las intervenciones arqueológicas del 2005 en la muralla oriental, $A A C$ 17, II, 61-84. (http://hdl.handle.net/10396/4433)

BARADEZ, J. (1957): Nouvelles fouilles à Tipasa: Survivances du culte de Baal et Tanit au Ier siècle de l'ère chrétienne, Libyca V, 221-276.

BARADEZ, J. (1968): Les nécropoles de Tipasa: tombes du cimetière occidental côtier, AntAfr 2, 77-93. DOI: http://dx.doi.org/10.3406/antaf.1968.890
BARATTA, G. (2006): Alcune osservazioni sulla genesi e la diffusione delle cupae, L'Africa Romana XVI (Rabat 2004), Roma, 1669-1682.

BENDALA, M. (2006): Hispania/España: un Oriente en Occidente, Boletín de la Asociación Española de Amigos de la Arqueología, 44, 369-385.

BENDALA, M. (2009): Continuidad y renovación en los centros sacros de las ciudades hispanorromanas, Santuarios, oppida y ciudades: arquitectura sacra en el origen y desarrollo urbano del mediterráneo occidental, IV Simposio de Arqueología de Mérida, 345-370.

BENDALA, M. (2010): Baelo Claudia y su personalidad ciudadana y urbana: Diálogo desde el estudio y la amistad, Pallas 82 , Hommage à Pierre Sillières, 465-482.

BERTHIER, A (2000): Tiddis. Cité Antique de Numidie, Paris.

BONNEVILLE, J.-N.; DARDAINE, S.; LE ROUX, P. (1988): Belo V. L'épigraphie. Les inscriptions romaines de Baelo Claudia, Madrid.

BOURGEOIS, A.; DEL AMO, M. (1970): Chronique. La quatrième campagne de fouilles à Belo-Bolonia (province de Cadix) en 1969, MCV, VI, 465-480 (http://www.persee.fr/web/revues/home/prescript/article/casa_0076-230x_1970_ num_6_1_1029)

CHAVES, F. (1979): Las monedas Hispano-Romanas de Carteia, Barcelona.

CHRISTOL, M. (1985): Les hommages publics de Volubilis: épigraphie et vie municipale, L'Africa Romana III, (Sassari 1986), 83-96.

CINTAS, P. (1949): Fouilles puniques à Tipasa, Alger.

CRESSIER, P.; MORET, P. (2007): La Casa de Velázquez y la arqueología: algunos apuntes históricos, Las Instituciones en el origen y desarrollo de la arqueología en España (M. Belén, J. Beltrán, eds.), Sevilla, 343-360.

DÍAZ-ANDREU, M. (1997): Nación e Internacionalización. La arqueología en España en las tres primeras décadas del siglo XX, La cristalización del pasado: Génesis y desarrollo del Marco institucional de la arqueología en España (G. Mora, M. Díaz-Andreu, eds.), Málaga, 403-416.

DOMERGUE, C. (2006): Á cinquante ans d'intervalle: Bélo 1916, Bélo 1966, Actas I Jornadas Internacionales de Baelo Claudia: Balance y perspectivas (1966- 2004) Cádiz, 9-35.

FÉVRIER, P. A. (1967): La nécropole orientale de Tiddis. Fouilles de Mai-Juillet 1967, Bulletin d'Archéologie Algérienne, IV, 41-100.

FITA, F. (1907): Noticias, Boletín de la Real Academia de la Historia $\mathrm{LI}, 145$.

FITA, F. (1908): Inscripciones romanas y visigodas de Tarifa, Ronda y Morón de la Frontera, Boletín de la Real Academia de la Historia LIII, 344-351.

FURGUS, J. (1907): Les ruines de Bélon, province de Cadix (Espagne), Annales de la Société d'Archéologie de Bruxelles XXI, 149-160. 
FURGUS, J. (1909): Antigüiedades romanas en la costa gaditana, Razón y Fe XXI, 2, 205-217.

GARCÍA Y BELLIDO, A.; NONY, D. (1969): Les fouilles de la Casa de Velázquez à Belo-Bolonia (Cádiz) en 1968, $M C V$ V, 465-478 (http://www.persee.fr/web/revues/ home/prescript/article/casa_0076-230x_1969_ num_5_1_1008).

GARCÍA-BELLIDO, M. P.; BLÁZQUEZ, C. (2001): Diccionario de cecas y pueblos hispánicos, Madrid

GARCÍA, I. (2008): Una aproximación al mundo funerario en Baelo Claudia, Vida y muerte en la Historia de Cádiz. (F.J. Guzmán, V. Castañeda, eds.), Cádiz, 103-124.

GARCÍA, I.; MUÑOZ, Á. (2009): Jules Furgus en Baelo Claudia. Pionero y precursor de la arqueología en el Campo de Gibraltar, Cuadernos de Historia y Patrimonio Cultural del Bajo Segura 2, 37-46.

JIMÉNEZ, A. (2007): Culto a los ancestros en época romana. Los cipos funerarios de la necrópolis de Baelo Claudia, AEA, 80, 75-106 (http://aespa.revistas.csic.es/index. php/aespa/article/view/28/28).

JIMÉNEZ, A. (2007b): A Critical Approach to the Concept of Resistance. New 'Traditional' Rituals and Objetcs in Funerary Contexts of Roman Baetica, TRAC 2007, 15-30.

JIMÉNEZ, A. (2008): Imagines Hibridae, una aproximación post-colonialista al estudio de las necrópolis de la Bética, Anejos de AEA XLIII, Madrid.

JODIN, A. (1987): Volubilis Regia Iubae. Contribution à l'étude des civilisations du Maroc antique preclaudien, Paris.

JULIA, D. (1965): Les monuments funéraires en forme de demicylindre dans la province romaine de Tarragonaise, MCV I, 29-54.

LANCEL, S. (1968): Tipasitana III: la nécropole pré-romaine occidentale de Tipasa. Rapport préliminaire (campagnes de 1966 et 1967), Bulletin d'Archéologie Algérienne III, 85-166.

LANCEL, S. (1970): Tipasitana IV: la Nécropole romaine occidentale de la porte de Césarée, Rapport préliminaire, Bulletin d'Archéologie Algérienne IV, 149-266.

LEFEBVRE, S. (2006): Les migrations des Africani en Péninsule Ibérique : quelle verité?, Migrare. La Formation des élites dans l'Hispanie Romaine (A. Caballos, S. Demougin, eds.), Bordeaux, 101-203.

LÓPEZ CASTRO, J. L.; BELMONTE, J. A. (2012): Pervivencias de la antroponimia fenicia en época romana en la Península Ibérica, La etapa neopúnica en Hispania y el Mediterráneo centro-occidental: identidades compartidas (B. Mora, G. Cruz, eds.), Sevilla, 141-164.

MAIER, J. (1999): Jorge Bonsor (1855-1930). Un académico correspondiente de la Real Academia de la Historia y la Arqueología Española, Madrid.

MERGELINA, C. (1927): La necrópoli Hispano-Romana de Baelo, Actas y Memorias de la Sociedad Española de Antropología Etnografía y Prehistoria VI, Mem. LIV.
MORET, P.; MUÑOZ, Á.; GARCÍA, I; CALLEGARIN, L.; PRADOS, F. (2008): El oppidum de la Silla del Papa (Tarifa, Cádiz) y los orígenes de Baelo Claudia, Aljaranda 68, 2-8. (http://www.aytotarifa.com/cultura/aljaranda/A68/arqueologia.pdf).

MORET, P.; FABRE, J.-M.; GARCIA, I.; PRADOS, F.; CONSTANS A. (2010): La Silla del Papa (Tarifa, Cádiz): bilan de trois années de recherches, Pallas, 82, Hommage à Pierre Sillières, 441-464.

MUÑOZ, Á.; GARCÍA, I.; PRADOS, F. (2009): Espacios jerarquizados y áreas funerarias en la necrópolis oriental de Baelo Claudia (Tarifa, Cádiz). Nuevas perspectivas de estudio, Jorge Bonsor y la recuperación de Baelo Claudia (19171921), Sevilla, 59-77.

PADILLA, A. (2010): Algunas notas acerca de la élite del municipio romano de Baelo, Habis 41, 185-203.

PARIS, P.; BONSOR, G.; LAUMONIER, A.; RICARD, R.; MERGELINA, C. (1923): Fouilles de Belo (Bolonia, province de Cádix, 1917-1921). I. La Ville et ses dépendences, Bordeaux

PARIS, P.; BONSOR, G.; LAUMONIER, A.; RICARD, R.; MERGELINA, C. (1926): Fouilles de Belo (Bolonia, province de Cádix, 1917-1921). II. La Nécropole, Bordeaux.

PONSICH, M. (1970): Recherches Archéologiques à Tanger et dans sa Région, Paris.

PONSICH, M. (1988): Aceite de oliva y salazones de pescado. Factores geoeconómicos de Bética y Tingitana, Madrid.

PRADOS, F. (2008): Arquitectura púnica. Los monumentos funerarios, Anejos de AEA XLIV, Madrid.

PRADOS, F. (2011): La necrópolis oriental de Baelo Claudia (Tarifa, Cádiz) en el contexto de la religiosidad púnico-mauritana. Una lectura a partir de las últimas actuaciones arqueológicas, Zephyrus 68, 191-210 (http://campus.usal. es/ revistas_trabajo/index.php/0514-7336/article/ view/8758/9289).

PRADOS, F.; GARCÍA, I. (2009): Aproximación al paisaje funerario de la necrópolis oriental de Baelo Claudia (Tarifa, Cádiz). Una lectura social, Aljaranda 72, 4-12 (http:// www.aytotarifa.com/cultura/aljaranda/A72/archivos/funerario.pdf)

PRADOS, F.; GARCÍA, I. (2010): Nuevas actuaciones arqueológicas en la necrópolis hispanorromana de Baelo Claudia (Tarifa, Cádiz). Balance de la campaña de 2009 y perspectivas, Aljaranda 77, 4-12 (http://www.aytotarifa.com/ cultura/aljaranda/A77/necropolis.pdf).

PRADOS, F.; GARCÍA, I.; JIMÉNEZ, H. (2013): Excavación arqueológica en la necrópolis de Baelo Caudia. Novedades de la campaña de 2012, Aljaranda 84, 6-14.

PRADOS, F.; MUÑOZ, Á; GARCÍA, I.; MORET, P. (2012): Bajar al mar y ihacerse romano? De la Silla del Papa a Baelo Claudia, La etapa neopúnica en Hispania y el Mediterráneo centro-occidental: identidades compartidas (B. Mora, G. Cruz, eds.), Sevilla, 301-330. 
REMESAL, J. (1979): La necrópolis sureste de Baelo, EAE, 104 Madrid.

ROMERO, E. (1908): Las ruinas de Carija y Bolonia. Boletín de la Real Academia de la Historia LIV, 422- 426.

SANMARTÍN, J. (1994): Toponimia y antroponimia: fuentes para el estudio de la Cultura Púnica de España, El Mundo Púnico. Historia, sociedad y cultura, Murcia, 227-250.

SILLIÈRES, P. (1997): Baelo Claudia. Una Ciudad romana de la Bética, Madrid.

SILLIÈRES, P. (2005): Las investigaciones arqueológicas en Baelo, Aljaranda 59, 8- 13.

TUPMAN, C. (2012): The cupae ot the Hispaniae: distribution, origins and functions, Las cupae hispanas: origen, difusión, uso, tipología (J. Andreu, ed.), Zaragoza, 3-24.

VAQUERIZO, D. (2006): Sobre la tradición púnica, o los influjos norteafricanos, en algunas manifestaciones arqueológicas del mundo funerario hispano-bético de época pleno imperial. Una revisión crítica, El concepto de lo provincial en el mundo antiguo. Homenaje a la profesora Pilar León Alonso, Córdoba, 317-363.

VAQUERIZO, D. (2010): Necrópolis urbanas en Baetica, Documenta 15, Tarragona.

VAQUERIZO, D. (2011): Espacios, usos y hábitos funerarios en la Hispania romana: reflexiones y últimas novedades, Mors Omnibus Instat. Aspectos arqueológicos, epigráficos y rituales de la muerte en el occidente romano, Madrid.

VILLAVERDE, N. (2001): Tingitana en la Antigüedad Tardía (siglos III-VIII), Real Academia de la Historia, Madrid.

VV.AA. (2009): Jorge Bonsor y la recuperación de Baelo Claudia (1917- 1921), Sevilla.

WIEGELS, R. (1985): Tribusinschriften des römischen Hispanien, Berlin.

ZANKER, P. (2000): The city as symbol: Rome and the creation of an urban image, Romanization and the City. Creation, Transformations and Failures (E. Fentress, ed.), Journal of Roman Archaeology, Suppl. Series, 38, 25-41. 